\title{
Cumulative asbestos exposure and mortality from asbestos related diseases in a pooled analysis of 21 asbestos cement cohorts in Italy
}

Ferdinando Luberto ${ }^{1}$, Daniela Ferrante ${ }^{2,3^{*}}$, Stefano Silvestri ${ }^{2,3}$, Alessia Angelini ${ }^{2,3}$, Francesco Cuccaro ${ }^{4}$, Anna Maria Nannavecchia ${ }^{4}$, Enrico Oddone ${ }^{5}$, Massimo Vicentini ${ }^{1}$, Francesco Barone-Adesi ${ }^{6}$, Tiziana Cena ${ }^{2,3}$, Dario Mirabelli ${ }^{7}, 17$, Lucia Mangone ${ }^{1}$, Francesca Roncaglia ${ }^{1}$, Orietta Sala ${ }^{8}$, Simona Menegozzo ${ }^{9}$, Roberta Pirastu ${ }^{10}$, Danila Azzolina ${ }^{2,3}$, Sara Tunesii ${ }^{2,3}$, Elisabetta Chellini ${ }^{11}$, Lucia Miligi ${ }^{11}$, Patrizia Perticaroli ${ }^{12}$, Aldo Pettinari ${ }^{12}$, Vittoria Bressan ${ }^{13}$, Enzo Merler ${ }^{14}$, Paolo Girardi ${ }^{13}$, Lucia Bisceglia ${ }^{15}$, Alessandro Marinaccio ${ }^{16}$, Stefania Massari ${ }^{16}$, Corrado Magnani ${ }^{2,3,17}$ and the working group

\begin{abstract}
Background: Despite the available information on cancer risk, asbestos is used in large areas in the world, mostly in the production of asbestos cement. Moreover, questions are raised regarding the shape of the dose response relation, the relation with time since exposure and the association with neoplasms in various organs. We conducted a study on the relationship between cumulative asbestos exposure and mortality from asbestos related diseases in a large Italian pool of 21 cohorts of asbestos-cement workers with protracted exposure to both chrysotile and amphibole asbestos.
\end{abstract}

Methods: The cohort included 13,076 workers, 81.9\% men and 18.1\% women, working in 21 Italian asbestos-cement factories, with over 40 years of observation. Exposure was estimated by plant and period, and weighted for the type of asbestos used. Data were analysed with consideration of cause of death, cumulative exposure and time since first exposure (TSFE), and by gender. SMRs were computed using reference rates by region, gender and calendar time. Poisson regression models including cubic splines were used to analyse the effect of cumulative exposure to asbestos and TSFE on mortality for asbestos-related diseases. 95\% Confidence Intervals (Cl) were computed according to the Poisson distribution.

Results: Mortality was significantly increased for 'All Causes' and 'All Malignant Neoplasm (MN)', in both genders. Considering asbestos related diseases (ARDs), statistically significant excesses were observed for MN of peritoneum (SMR: men 14.19; women 15.14), pleura (SMR: 22.35 and 48.10), lung (SMR: 1.67 and 1.67), ovary (in the highest exposure class SMR 2.45), and asbestosis (SMR: 507 and 1023). Mortality for ARDs, in particular pleural and peritoneal malignancies, lung cancer, ovarian cancer and asbestosis increased monotonically with cumulative exposure. Pleural MN mortality increased progressively in the first 40 years of TSFE, then reached a plateau, while peritoneal MN showed a continuous increase. The trend of lung cancer SMRs also showed a flattening after 40 years of TSFE. Attributable proportions for pleural, peritoneal, and lung MN were respectively 96,93 and 40\%.

(Continued on next page)

\footnotetext{
* Correspondence: daniela.ferrante@med.uniupo.it

${ }^{2}$ Unit of Medical Statistics and Cancer Epidemiology, Department of

Translational Medicine, University of Eastern Piedmont, via Solaroli 17, 28100

Novara, Italy

${ }^{3}$ CPO-Piedmont, Novara, Italy

Full list of author information is available at the end of the article
}

(c) The Author(s). 2019 Open Access This article is distributed under the terms of the Creative Commons Attribution 4.0 International License (http://creativecommons.org/licenses/by/4.0/), which permits unrestricted use, distribution, and reproduction in any medium, provided you give appropriate credit to the original author(s) and the source, provide a link to the Creative Commons license, and indicate if changes were made. The Creative Commons Public Domain Dedication waiver (http://creativecommons.org/publicdomain/zero/1.0/) applies to the data made available in this article, unless otherwise stated. 
(Continued from previous page)

Conclusions: Mortality for ARDs was associated with cumulative exposure to asbestos. Risk of death from pleural MN did not increase indefinitely with TSFE but eventually reached a plateau, consistently with reports from other recent studies.

Keywords: Asbestos, Asbestos-cement, Dose response relationship, Mesothelioma, Lung cancer, Ovarian Cancer, Epidemiology

\section{Introduction}

Asbestos fibres in their different mineralogical forms of chrysotile and amphiboles are a well known carcinogen acting on the respiratory tract and other organs. In 2009, the International Agency for Research on Cancer (IARC) updated the evaluation of asbestos fibres and confirmed that all types of asbestos cause malignant mesothelioma (MM), and cancer of lung, larynx and ovary in humans (Class 1), while the evidence was lower for pharynx, stomach and colorectal cancer (Class 2A) [1]. The evidence of association shows a complex relation between the amount of exposure (dose and duration) and its time pattern (latency and time since cessation) [2] that still deserves clarification from large studies investigating dose, latency and other time related factors.

The asbestos cement industry was the largest asbestos consumer, using $85 \%$ of asbestos produced or imported in European countries [3]. It employed a large number of workers: asbestos cement workers in Italy were estimated in 9000 in 1979 and 5000 in 1987, active in a large number of plants, most of which were of small or medium size $[4,5]$.

Several mortality studies on asbestos cement workers have been conducted in the past decades in Canada [6], United States [7], Israel [8], Italy [9-18], and in other European countries [19-28]. Only few studies analysed the mortality by gender $[12,14,18,19,21,25,27,28]$, generally including small numbers of female workers and observed deaths. Moreover, some relevant questions, such as the trend of the risk of mesothelial $\mathrm{MN}$ with $\mathrm{cu}$ mulative dose and latency, are still debated [14, 29-31] and are of interest for both preventive and compensation purposes. The results of cohort studies on asbestos cement workers are also of interest for the countries where the product is still made. In all countries, the basic production process is the "Hatschek process", first patented in late nineteenth century. The information on present asbestos cement industry are scanty and refer of poor working conditions even in recent years [32-35].

The present multicentre investigation is part of a larger project on epidemiological surveillance of asbestos workers [36]. It aimed at investigating mortality by cause, gender, and time-related variables, in particular cumulative dose and latency, with particular attention to the neoplasms with sufficient or limited evidence of association with asbestos [1].

\section{Material and methods}

This study includes 21 asbestos cement factories, part of the Italian pooled cohorts of asbestos workers [36]. The inclusion criteria for individual cohorts were availability of a data set with updated follow-up and a period of observation longer than 40 years. The main characteristics of the cohorts are reported in Additional file 1: Table S1.

The initial study base included 14,779 workers: 12,136 men $(82.1 \%)$ and 2643 women (17.9\%). During the preliminary analyses $11.5 \%$ of records (1703) were excluded, distributed over most of the cohorts, for the following reasons: first employment after 1992 (approval of the asbestos ban in Italy), conflicting dates, incomplete working periods, or unlikely age at hiring or end of employment (Hiring $<13$ or $>70$; End $>70$ ). The two cohorts of the Eternit-Naples and Fibronit-Broni factories were limited to the workers hired after January 1st, 1950 because the quality of follow-up (FU) data was too limited before that date. Workers employed in more than one plant were identified, and their separate work histories were merged, except for cohort specific analyses. Figure 1 shows the flow chart for the construction of the pooled cohort. The final data set includes 12,578 workers, $81.7 \%$ men and $18.3 \%$ women.

Vital status was ascertained through the Registrar Office of the municipality of last residence. The FU date was December 31st, 2010 for the three cohorts of Tuscany and the cohort of Lazio, and December 31st, 2012 or later for the other 17 cohorts. For subjects lost to FU, the last contact date was used. Causes of death until 1985 were obtained from the municipalities, afterwards from Local Health Authorities (LHA). Causes were coded according to the 8th, 9th, or 10th Revisions of the International Classification of Diseases (ICD), according to the date of death. The ICD 10th revision is used in Italy from 2003 [37]. Additional file 1: Table S2 presents the causes of death considered and the corresponding codes. We included 'a priori' in the analyses the causes of death associated with asbestos exposure, in particular asbestosis, malignant neoplasms (MN) of pleura and peritoneum, larynx, lung, and ovary, and the other neoplasms with limited evidence of association according to IARC classification [1]. Causes of death reported in association with the Healthy Worker Effect (HWE) were considered in the analyses, in particular cardiovascular diseases, digestive diseases, respiratory diseases, psychiatric diseases, 


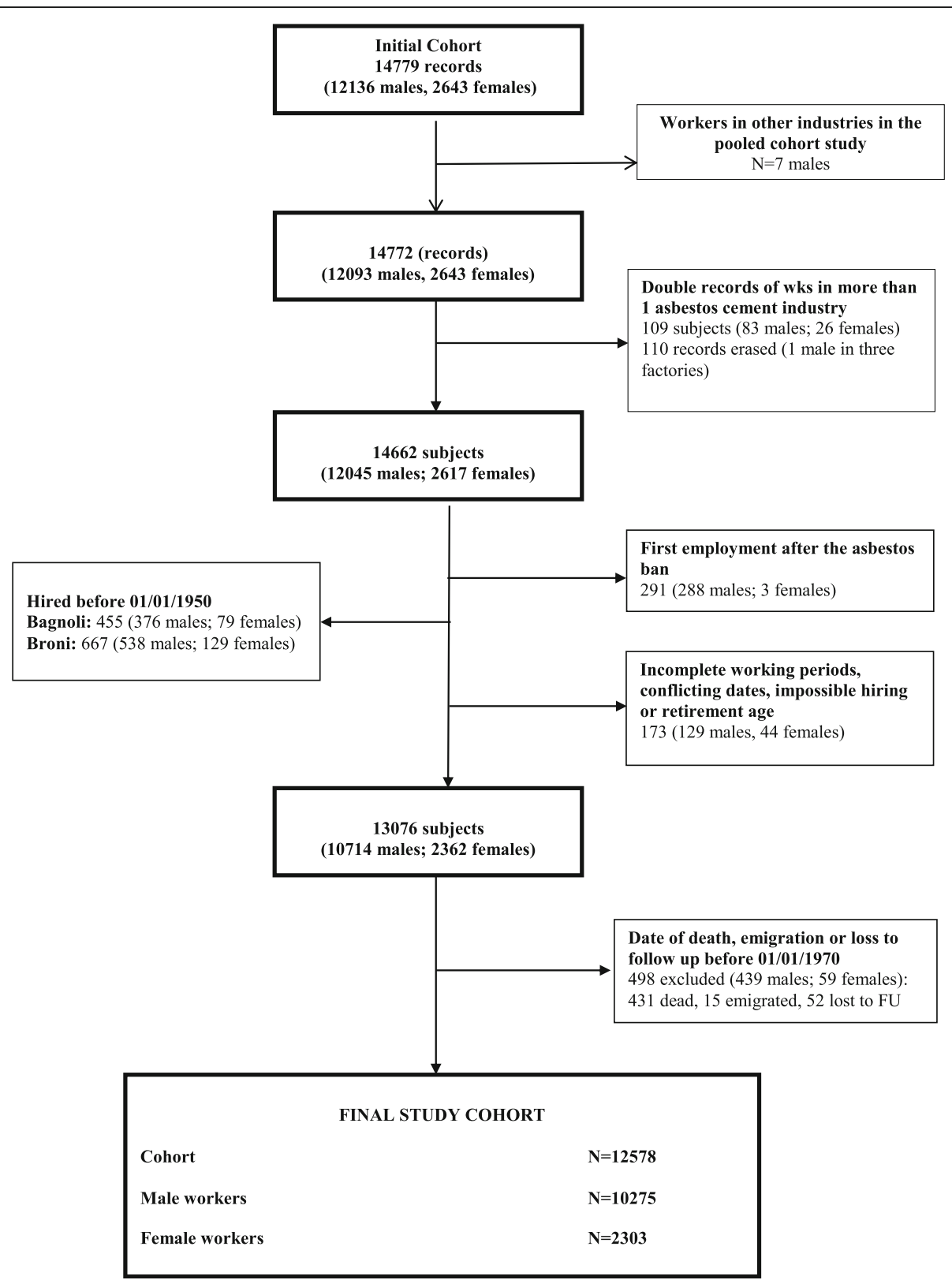

Fig. 1 Pooled cohort study of asbestos cement workers in Italy. Flow chart: exclusion criteria and number of subjects included in the analyses

neurological diseases, digestive diseases and genitourinary diseases, as well as the total mortality [38]. Cardiovascular diseases and respiratory diseases were also evaluated as related to smoking.

The production cycle of asbestos cement industries in Italy was similar in the different companies and was based on the "Hatschek process" [39]. The dry mixture used for most productions contained about $13-15 \%$ of asbestos [39], mostly chrysotile from Italy, Canada and former Soviet Union. Amphibole fibres, mostly crocidolite from Australia and South Africa and a small percentage of amosite from South Africa, were also used depending on the product type. In the production of high-pressure pipes the percentage of asbestos was higher, reaching $20 \%$ (usually $1 / 3$ of crocidolite, $1 / 3$ of long chrysotile from Canada, 1/3 Balangero chrysotile). Asbestos exposure was measured in some companies at different times and the results have been reported in scientific papers $[10-14,16,18]$, in courts during litigations and in reports from industrial hygiene laboratories of Italian public health agencies or universities. The reported levels of exposure were very high before 1980 (0.2-45 fibres/cc), intermediate between 1980 and 1989 (0.2$11)$ and lower after $1989(<0.1-0.3)$. 
The main products were plain or corrugated sheets, pipes, slabs, tanks, chimneys and other products. In many factories, production also included the manual manufacture of small pieces. The asbestos cement manufacturing process can be reassumed in three stages: mixing, moulding and finishing. Asbestos exposure was high in mixing and finishing while in moulding area, exposure was lower due to the materials being wet. Diffusion of dust from higher to lower exposure areas was common, especially in the plants without physical barriers to separate the areas. These two main modes of exposure have been defined as "direct" for the high exposure areas and "indirect" for the lower ones. Indirect exposure regarded in particular the workers of the moulding workshops, while direct exposure affected the workers employed in mixing and finishing operations.

Two expert industrial hygienists (AA and SS) collected and evaluated the information regarding the use of asbestos, the work process, the plant layout and the measurements of airborne asbestos fibres, for each plant and year of activity. Considered data sources included both published and unpublished reports, in particular company reports, surveys of exposure, judicial examinations, and reports collected from workers [40]. For each factory and calendar period, the original investigators had provided available information, including estimates of the proportion of exposed workers, the percentage of typical working time in tasks with asbestos exposure and the range of minimum and maximum level of asbestos concentration separately for direct and indirect exposures. Company-specific data were checked against those from other factories included in our pooled study and literature data to identify possible inconsistencies (i.e. differences that could not be explained by plant-specific features) and to fill data gaps (e.g. by deriving timetrends for asbestos concentration).

For each plant and periods, the experts estimated the proportion of workers exposed, the percentage of typical working time in tasks with asbestos exposure and the range of minimum and maximum concentration of asbestos airborne fibres $(\mathrm{f} / \mathrm{ml})$, separately for direct and indirect exposure.

Tasks and jobs of individual workers were not known, therefore plant and period-specific data were used to compute for each plant and year an Average Exposure Index (AEI) to be applied to all members of a given cohort. First, the ranges of concentration for direct and indirect exposures were summarized in single values by computing the geometric mean between minimum and maximum levels, adjusting for the average proportion of time in tasks with asbestos exposure. Such geometric means were taken as estimates of the time-weighted average level of exposure for direct and indirect exposures, specific for factory and period. The AEI value was calculated for each plant and year as the average of direct and indirect exposures, weighted by the respective proportional size of the workforce, according to the following formula:

$$
A E I_{p y}=\left(E_{d p y} * w_{d p y}+E_{i p y} * w_{i p y}\right)
$$

where $E=$ Exposure geometric mean, $w=$ proportional size of the workforce and $d=$ direct, $i=$ indirect exposure, and $p=$ plant, $y=$ year.

From the AEI a Cumulative Average Exposure Index (CEI) was computed for the occupational history of each worker summing the contribution of all periods of activity:

$$
C E I=\sum_{p y} A E I_{p y}
$$

Additionally, a fibre-type-weighted-AEI was computed based on the proportion of chrysotile $\left(\mathrm{CH}_{\mathrm{py}}\right)$, amosite $\left(A_{p y}\right)$, and crocidolite $\left(\mathrm{CR}_{\mathrm{py}}\right)$ used yearly in each plant. The weights were the MM potency factors for chrysotile, amosite and crocidolite (respective 1:14:71) as estimated by Hodgson and Darnton [41]. The fibre-type-weightedAEI provided the average chrysotile equivalent asbestos concentration in fibres per ml. It was computed as:

$$
\text { fibre-type-weighted } A E I_{p y}=A E I_{p y} *\left(1 * C H_{p y}+14 * A_{p y}+71 * C R_{p y}\right)
$$

A fibre-type-weighted-Cumulative Exposure Index (fibre-type-weighted-CEI) was computed for each worker summing the fibre-type-weighted AEI for all periods of activity.

$$
\text { fibre-type-weighted-CEI }=\sum_{p y} \text { fibre-type-weighted-AEI } I_{p y}
$$

On a heuristic ground, we used the same weights also for the analysis of other Asbestos Related Diseases (ARD)s. Sensitivity analyses were conducted using factors derived by other authors $[42,43]$.

The dimension of AEI was a concentration, expressed in fibres/ml and the dimension of the fibre-type-weightedAEI was the equivalent concentration of chrysotile asbestos fibres, in fibres/ml. CEI and fibre-type-weighted-CEI had the dimension of concentration times years (f/ ml*year), the latter being the equivalent concentration of chrysotile asbestos fibres times years. Additional file 1: Table S3 data presents the exposure indexes by plant and period of activity.

Standardized Mortality Rates (SMR) were stratified by gender, and 'a priori' defined classes of calendar time, cumulative exposure, duration and Time Since First Exposure (TSFE) (also known as 'latency'). For the purpose of present analyses, CEI was categorized in tertiles, based on the distribution of the total cohort. Class limits were: 5.0 and $48.5 \mathrm{f} / \mathrm{ml}^{*}$ years for CEI (median 22.0); 54.0 
and 620.0 (median 248.0) $\mathrm{f} / \mathrm{ml}$ "years for fibre-typeweighted-CEI. Duration of exposure was calculated by summing up all the work periods since the date of first employment. TSFE was calculated from the date of first employment until the most recent date of observation. The same categories were used for Poisson regression models.

The numbers of expected deaths (used for SMRs) were based on regional mortality rates provided by the National Institute of Statistics - ISTAT (Rome, Italy) by cause, gender, and year, available from 1970 [37]. Correspondingly, all analyses (including Poisson regression) were restricted to person years (PY) and events occurring after January 1st 1970; subjects lost to follow-up or dead before that date were excluded. For each cohort, expected deaths were calculated with the application of the corresponding regional rates. Multivariable analyses were carried out using Poisson regression [44]. Chi square test for linear trend of SMRs was calculated when appropriate [44]. 95\% Confidence Intervals (CI) were computed according to the Poisson distribution of observed deaths [44]. Statistical significance was set at 5\%.

Models including restricted cubic splines (4 degrees) on fibre-type-weighted-CEI, TSFE and period were fitted to take into account the possible non linear relation between the predictive variables and mortality [45]. In these models, fibre-type-weighted-CEI and TSFE were analysed as continuous variables.

Data were prepared using MS Access and SAS 9.2. Analyses were carried out using OCMAP plus, STATA 11, SAS 9.2 and R 3.2.5 with Survival and RMS packages [46].

\section{Results}

Table 1 presents the distribution of cohort members (10, 275 male and 2303 female workers) and person-years (PYs) (309,675 in men and 79,241 in women), by vital status, year, age at first exposure (defined as the beginning of employment period) and duration of employment. Forty four percent of men and $54.1 \%$ of women were alive at the end of FU; 54.4 and $44.9 \%$ died, and 1.3 and $0.9 \%$ emigrated or were lost at FU. The cause of death was known for $95.9 \%$ of male and $97.6 \%$ of female decedents. Year of first exposure was before 1970 for $70.2 \%$ of workers; $60.1 \%$ were younger than 30 at the beginning of activity; duration of employment was shorter than 20 years in $76 \%$. Additional file 1: Table S4 presents the distribution of PY by age class and gender.

Table 2 presents mortality figures (observed and expected deaths, SMRs and 95\% CI), by gender. Overall mortality and mortality for all $\mathrm{MN}$ were significantly increased in both sexes. Mortality was significantly higher than expected in both sexes for the MN of the respiratory tract category, and for $\mathrm{MN}$ of the lung, pleura, and peritoneum, and also for MN of unspecified site among men. Mortality from ovarian MN was higher than expected even if the excess was not statistically significant. Mortality from MN of larynx, pharynx, stomach, colon and rectum was not significantly higher than expected. Mortality from neoplasms of digestive tract excluding peritoneal MM was very close to expected in both genders (Men: SMR $=1.00$; 95\% CI: 0.92-1.09; Women: SMR $=1.18 ; 95 \%$ CI: $0.96-1.43)$. Mortality from asbestosis was extremely high (348 deaths in men - SMR: 507- and 51 in women -SMR: 1023), and determined an excess for the general categories of pneumoconiosis and respiratory diseases. Thirty three deaths were attributed to 'other pneumoconioses' (32 in men and 1 in women), including 21 silicoses and 12 'unspecified pneumoconioses'; the excess was statistically significant in men. In men, mortality was significantly lower than expected for neurological and cardiovascular diseases. In women for no causes of death mortality was significantly lower than expected. Mortality from unspecified causes $(0.1 \%$ of total deaths in men and $0.2 \%$ in women) was increased in both sexes.

Mortality by tertile of cumulative exposure is presented in Table 3. The table also includes the $p$-value of the Chi-square test for linear trend. A statistically significant increasing trend was observed in both sexes for the MN of the pleura and of the peritoneum and for asbestosis, as well as for total mortality and total malignancies. The trend for lung cancer mortality was statistically significant in men, while it was irregular in women. Women showed a statistically significant trend also for ovarian cancer, and the SMR was increased in the upper tertile of cumulative exposure. A negative trend was observed in men for cardiovascular and for accidental deaths. The pattern of mortality from 'other pneumoconioses' by tertile of cumulative exposure suggested that at least a proportion of those cases are asbestosis cases: we observed an increasing trend, similar to that observed for the 'asbestosis' category but with lower SMRs: I tertile: 1 obs, 1.18 exp., SMR: 0.85 (95\% CI: 0.02-4.72); II tertile: 6 obs, 2.46 exp., SMR: 2,44 (95\% CI: 0.905.31); III tertile: 26 obs, 4.39 exp., SMR: 5.92 (95\% CI: 3.87-8.68) (data not tabulated).

Mortality by duration of employment is presented in Additional file 1: Table S5. Results were similar to the trends observed for cumulative exposure and are not discussed in details.

Table 4 shows mortality in relation to TSFE ("latency"). The analysis was limited to the causes selected 'a priori' because associated with asbestos exposure, and to some categories related to the HWE. In both genders, 'All causes' and 'All MN' mortality was lower or equal to expected in the first 19 years of TSFE, and increased afterwards. No case of pleural MN was observed in the first 10 years of TSFE. The trend for pleural MN showed 
Table 1 Pooled cohort study of asbestos cement workers in Italy. Descriptive analyses of the cohort

\begin{tabular}{|c|c|c|c|c|c|c|c|c|c|c|}
\hline & & \multicolumn{3}{|l|}{ Males } & \multicolumn{3}{|c|}{ Females } & \multicolumn{3}{|l|}{ Total } \\
\hline & & $\mathrm{n}$ & $\%$ & $P Y^{b}$ & $\mathrm{n}$ & $\%$ & $P Y^{b}$ & $\mathrm{n}$ & $\%$ & $P Y^{b}$ \\
\hline \multirow[t]{4}{*}{ Status at follow-up } & alive & 4559 & 44.4 & -- & 1247 & 54.1 & -- & 5806 & 46.1 & -- \\
\hline & deceased $^{a}$ & 5591 & 54.4 & -- & 1035 & 44.9 & -- & 6626 & 52.7 & -- \\
\hline & emigrated & 47 & 0.5 & -- & 11 & 0.5 & -- & 58 & 0.5 & -- \\
\hline & lost to follow-up & 78 & 0.8 & -- & 10 & 0.4 & -- & 88 & 0.7 & -- \\
\hline \multirow[t]{6}{*}{ Year of first exposure } & $<1950$ & 974 & 9.5 & 18112.3 & 473 & 20.5 & 12727.0 & 1447 & 11.5 & 30839.3 \\
\hline & 1950-1959 & 2124 & 20.7 & 59769.5 & 879 & 38.2 & 32382.6 & 3003 & 23.9 & 92152.1 \\
\hline & 1960-1969 & 3870 & 37.7 & 130476.4 & 512 & 22.2 & 19699.8 & 4382 & 34.8 & 150176.4 \\
\hline & 1970-1979 & 1831 & 17.8 & 62114.4 & 257 & 11.2 & 9247.6 & 2088 & 16.6 & 71362.0 \\
\hline & 1980-1989 & 1352 & 13.2 & 36766.5 & 178 & 7.7 & 5096.7 & 1530 & 12.2 & 41863.2 \\
\hline & 1990-1992 & 124 & 1.2 & 2435.4 & 4 & 0.2 & 87.1 & 128 & 1.0 & 2522.5 \\
\hline \multirow[t]{5}{*}{ Age at first exposure (years) } & $<20$ & 1570 & 15.3 & 53787.0 & 953 & 41.4 & 34310.6 & 2523 & 20.1 & 88097.6 \\
\hline & $20-29$ & 4255 & 41.4 & 138017.6 & 776 & 33.7 & 27258.9 & 5031 & 40.0 & 165276.5 \\
\hline & $30-39$ & 2673 & 26.0 & 77012.3 & 388 & 16.8 & 12297.4 & 3061 & 24.3 & 89309.6 \\
\hline & $40-49$ & 1343 & 13.1 & 32209.6 & 168 & 7.3 & 4946.0 & 1511 & 12.0 & 37155.7 \\
\hline & $50+$ & 434 & 1.2 & 8648.1 & 18 & 0.8 & 427.9 & 452 & 3.6 & 9076.1 \\
\hline \multirow[t]{5}{*}{ Duration of employment (years) } & $<10$ & 5439 & 52.9 & 183166.7 & 1330 & 57.8 & 49598.8 & 6769 & 53.8 & 232765.4 \\
\hline & $10-19$ & 2308 & 22.5 & 69308.8 & 469 & 20.4 & 16047.5 & 2777 & 22.1 & 85356.3 \\
\hline & $20-29$ & 1884 & 18.3 & 45219.6 & 351 & 15.2 & 10035.8 & 2235 & 17.8 & 55255.3 \\
\hline & $30+$ & 644 & 6.3 & 11979.5 & 153 & 6.6 & 3558.8 & 797 & 6.3 & 15538.3 \\
\hline & Total & 10275 & 100.0 & 309674.6 & 2303 & 100.0 & 79240.8 & 12578 & 100.0 & 388915.2 \\
\hline
\end{tabular}

${ }^{\mathrm{a}} 255$ causes of death unknown ( 230 males and 25 females, in both sexes $3.8 \%$ of decedents); ${ }^{\mathrm{b}}$ person-years computed from 1970

in both sexes increasing SMRs up to the 30-39 years class of TSFE, and a plateau or even a reduction at longer TSFE periods. No deaths were observed for MN of the peritoneum in the first two decades, while SMRs were increased from 20 to 29 years of TSFE in men and $40-49$ years in women $(p<0.01$ in both sexes) with no evidence of plateau. Lung cancer showed a trend similar to pleural MN: mortality was lower than expected in the first 10 years of TSFE, then increased to the highest SMR in the 30-39 year class, followed by a decrease. Laryngeal cancer mortality was below the expected values in the first 4 periods, and increased after 40-49 years of TSFE. Only 2 female cases of laryngeal cancer were observed. Deaths from ovarian cancer were observed only after 20 years of TSFE and the SMR was increased after 50 years of TSFE. There were no deaths from asbestosis in the first 10 years of TSFE in men and in the first 30 years in women. Subsequently, there was a continuous increase over the entire observation period, with SMRs higher in women. Mortality from cardiovascular diseases was lower than expected in all age categories for men but not for women.

Table 5 presents the results of Poisson regression analyses for pleural and peritoneal malignancies and lung MN. Several models were tested; the presented results correspond to the best fitting models, including different sets of variables according to the different diseases and sexes. All best fitting models included cumulative exposure (fibre-typeweighted-CEI). For pleural MN, the RR increased with cumulative exposure, while with TSFE it showed an increase in the first four decades, followed by a plateau, in both genders. For peritoneal MN, both genders showed a monotonic trend of increasing RR with increasing TSFE and cumulative exposure, albeit the small number of cases showed some irregularities for women. For lung neoplasm, in men RR showed an increase with cumulative exposure and a curvilinear trend for TSFE; for women, the model showed an increase of RR with cumulative exposure only from the lowest to the intermediate categories, with no further increase, and TSFE did not contribute to the model fit.

Figure 2 presents the cubic spline describing the relation of mortality rate from pleural (a), peritoneal (b) and lung $\mathrm{MN}$ (c) with cumulative exposure (fibre-type-weighted-CEI) and TSFE. For pleural neoplasm, mortality continuously increased with cumulative exposure, while it reached a plateau after 30 years of TSFE. Similar trends were observed for lung cancer, with a plateau becoming apparent after 40 years since first exposure. On the opposite, an increasing trend of mortality for peritoneal cancer was observed along the all range of fibre-type-weighted-CEI and TSFE. 
Table 2 Pooled cohort study of asbestos cement workers in Italy. Cause specific mortality by gender and selected diseases

\begin{tabular}{|c|c|c|c|c|c|c|c|c|c|c|}
\hline \multirow{3}{*}{$\frac{\text { Cause of death }}{\text { All causes }}$} & \multicolumn{5}{|l|}{ Males } & \multicolumn{5}{|c|}{ Females } \\
\hline & \multirow{2}{*}{$\frac{\mathrm{OBS}}{5591}$} & \multirow{2}{*}{$\begin{array}{l}\text { EXP } \\
4599.02\end{array}$} & \multirow{2}{*}{$\frac{\text { SMR }}{1.23 * *}$} & \multicolumn{2}{|l|}{$95 \% \mathrm{Cl}$} & \multirow{2}{*}{$\frac{\text { OBS }}{1035}$} & \multirow{2}{*}{$\begin{array}{l}\text { EXP } \\
771.34\end{array}$} & \multirow{2}{*}{$\frac{\mathrm{SMR}}{1.34^{* *}}$} & \multicolumn{2}{|l|}{$95 \% \mathrm{Cl}$} \\
\hline & & & & 1.19 & 1.26 & & & & 1.26 & 1.43 \\
\hline Malignant neoplasm (MN) & 2342 & 1589.36 & $1.47^{* *}$ & 1.41 & 1.53 & 414 & 242.81 & $1.71 * *$ & 1.55 & 1.88 \\
\hline MN lip, oral cavity and pharynx & 29 & 42.97 & $0.68 *$ & 0.45 & 0.97 & 5 & 2.56 & 1.95 & 0.63 & 4.56 \\
\hline MN digestive organs (incl peritoneum) & 639 & 544.87 & $1.17 *$ & 1.08 & 1.27 & 130 & 86.24 & $1.51 * *$ & 1.26 & 1.79 \\
\hline MN oesophagus & 39 & 31.89 & 1.22 & 0.87 & 1.67 & - & 1.72 & - & - & - \\
\hline MN stomach & 136 & 139.59 & 0.97 & 0.82 & 1.15 & 22 & 16.71 & 1.32 & 0.83 & 1.99 \\
\hline MN small intestine & 6 & 2.81 & 2.14 & 0.78 & 4.65 & - & 0.47 & - & - & - \\
\hline MN colon & 117 & 102.34 & 1.14 & 0.95 & 1.37 & 26 & 20.10 & 1.29 & 0.85 & 1.90 \\
\hline MN rectum & 40 & 45.90 & 0.87 & 0.62 & 1.19 & 11 & 7.74 & 1.42 & 0.71 & 2.54 \\
\hline MN of liver and intrahepatic bile ducts & 102 & 103.33 & 0.99 & 0.81 & 1.20 & 10 & 11.53 & 0.87 & 0.42 & 1.60 \\
\hline MN peritoneum & 102 & 7.19 & $14.19 * *$ & 11.57 & 17.23 & 31 & 2.05 & $15.14^{* *}$ & 10.29 & 21.50 \\
\hline MN respiratory organs & 1184 & 552.55 & $2.14 * *$ & 2.02 & 2.27 & 130 & 25.93 & $5.01 * *$ & 4.19 & 5.95 \\
\hline MN larynx & 50 & 41.83 & 1.20 & 0.89 & 1.58 & 2 & 0.63 & 3.16 & 0.38 & 11.42 \\
\hline MN lung & 820 & 490.25 & $1.67 * *$ & 1.56 & 1.79 & 38 & 22.82 & $1.67 * *$ & 1.18 & 2.29 \\
\hline MN pleura & 305 & 13.65 & $22.35 * *$ & 19.91 & 25.00 & 89 & 1.85 & $48.10^{* *}$ & 38.63 & 59.19 \\
\hline MN uterus & & & & & & 21 & 14.07 & 1.49 & 0.92 & 2.28 \\
\hline MN ovary & & & & & & 19 & 12.70 & 1.50 & 0.90 & 2.34 \\
\hline MN prostate & 93 & 96.74 & 0.96 & 0.78 & 1.18 & & & & & \\
\hline MN bladder & 82 & 70.79 & 1.16 & 0.92 & 1.44 & 6 & 3.50 & 1.71 & 0.63 & 3.73 \\
\hline MN kidney & 34 & 37.90 & 0.90 & 0.62 & 1.25 & 1 & 4.08 & 0.25 & 0.01 & 1.37 \\
\hline Leukemia and lymphoma & 125 & 108.04 & 1.16 & 0.96 & 1.38 & 22 & 20.52 & 1.07 & 0.67 & 1.62 \\
\hline MN unspecified site & 64 & 40.20 & $1.59 * *$ & 1.23 & 2.03 & 8 & 7.11 & 1.13 & 0.49 & 2.22 \\
\hline Psychiatric diseases & 40 & 38.79 & 1.03 & 0.74 & 1.40 & 17 & 12.81 & 1.33 & 0.77 & 2.13 \\
\hline Neurological diseases & 60 & 92.79 & $0.65 * *$ & 0.49 & 0.83 & 14 & 23.26 & 0.60 & 0.33 & 1.01 \\
\hline Cardiovascular diseases & 1444 & 1657.41 & $0.87 * *$ & 0.83 & 0.92 & 307 & 304.88 & 1.01 & 0.90 & 1.13 \\
\hline Respiratory diseases & 679 & 307.83 & $2.21 * *$ & 2.04 & 2.38 & 92 & 37.33 & $2.47 * *$ & 1.99 & 3.02 \\
\hline Bronchitis, emphysema, asthma & 150 & 127.31 & 1.18 & 1.00 & 1.38 & 16 & 10.60 & 1.51 & 0.86 & 2.45 \\
\hline Asbestosis & 348 & 0.69 & $507.22 * *$ & 455.32 & 563.41 & 51 & 0.05 & $1023.34 * *$ & 761.95 & 1345.52 \\
\hline Other pneumoconioses & 32 & 8.00 & $4.00 * *$ & 2.74 & 5.65 & 1 & 0.04 & 8.42 & 0.63 & 139.30 \\
\hline Digestive diseases & 276 & 281.56 & 0.98 & 0.87 & 1.10 & 45 & 40.54 & 1.11 & 0.81 & 1.49 \\
\hline Genitourinary diseases & 53 & 59.76 & 0.89 & 0.66 & 1.16 & 13 & 10.39 & 1.25 & 0.67 & 2.14 \\
\hline Accidents and violence & 221 & 234.61 & 0.94 & 0.82 & 1.08 & 35 & 28.69 & 1.22 & 0.85 & 1.70 \\
\hline Poorly specified causes & 77 & 29.82 & $2.58 * *$ & 2.04 & 3.23 & 24 & 8.37 & $2.87 * *$ & 1.84 & 4.27 \\
\hline Unknown causes (in "All causes" only) & 230 & & & & & 25 & & & & \\
\hline
\end{tabular}

OBS: observed; EXP: expected; SMR: standardized mortality ratio; Cl: confidence interval. * $p<0.05 ;{ }^{* *} p<0.01$

Analyses for cumulative exposure were repeated using both the unweighted CEI and the fibre-type-weightedCEI computed using the weights estimated by Garabrant et al. [42]. None of these analyses (not in details) showed relevant differences with the analyses presented in Tables 3 and 5 and in Fig. 2 and all confirmed the dose response trends with increasing exposure.

Analyses by period of first exposure are reported in Additional file 1: Table S6. Among workers with first employment in 1980-89, a statistically significant excess was observed for pleural MN and for asbestosis (1 case) among men (employed in 1980, aged 36, until 1994), and one case of $\mathrm{MN}$ of the pleura was observed in women.

\section{Discussion}

Our study is a pooled analysis of 21 cohorts of asbestos cement workers, which accounted for a wide fraction of workers employed in the asbestos cement production in 


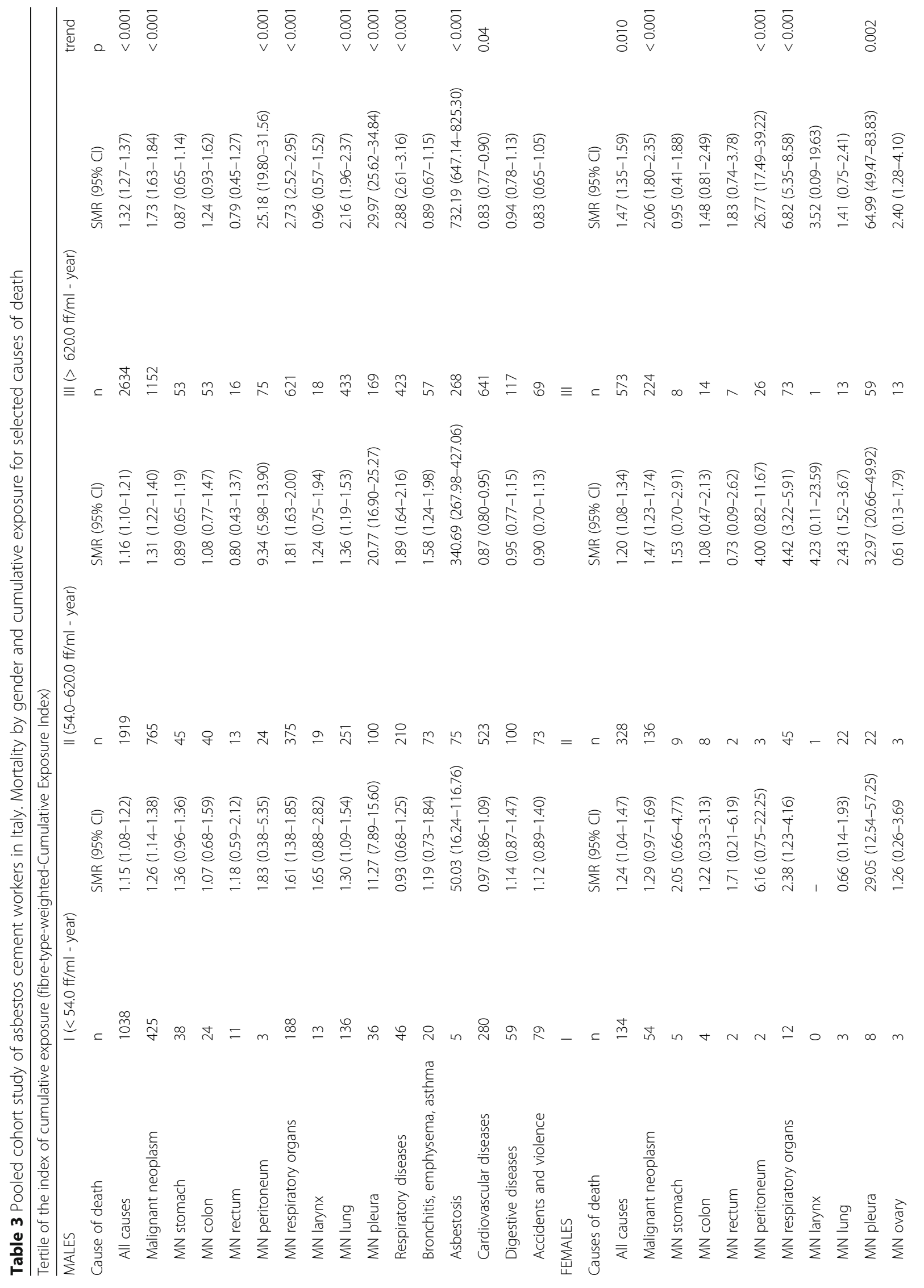




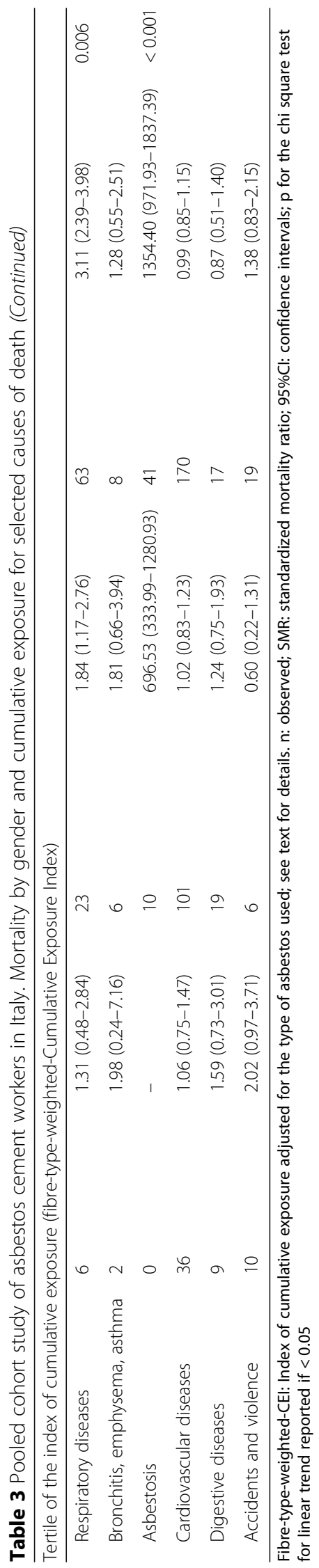




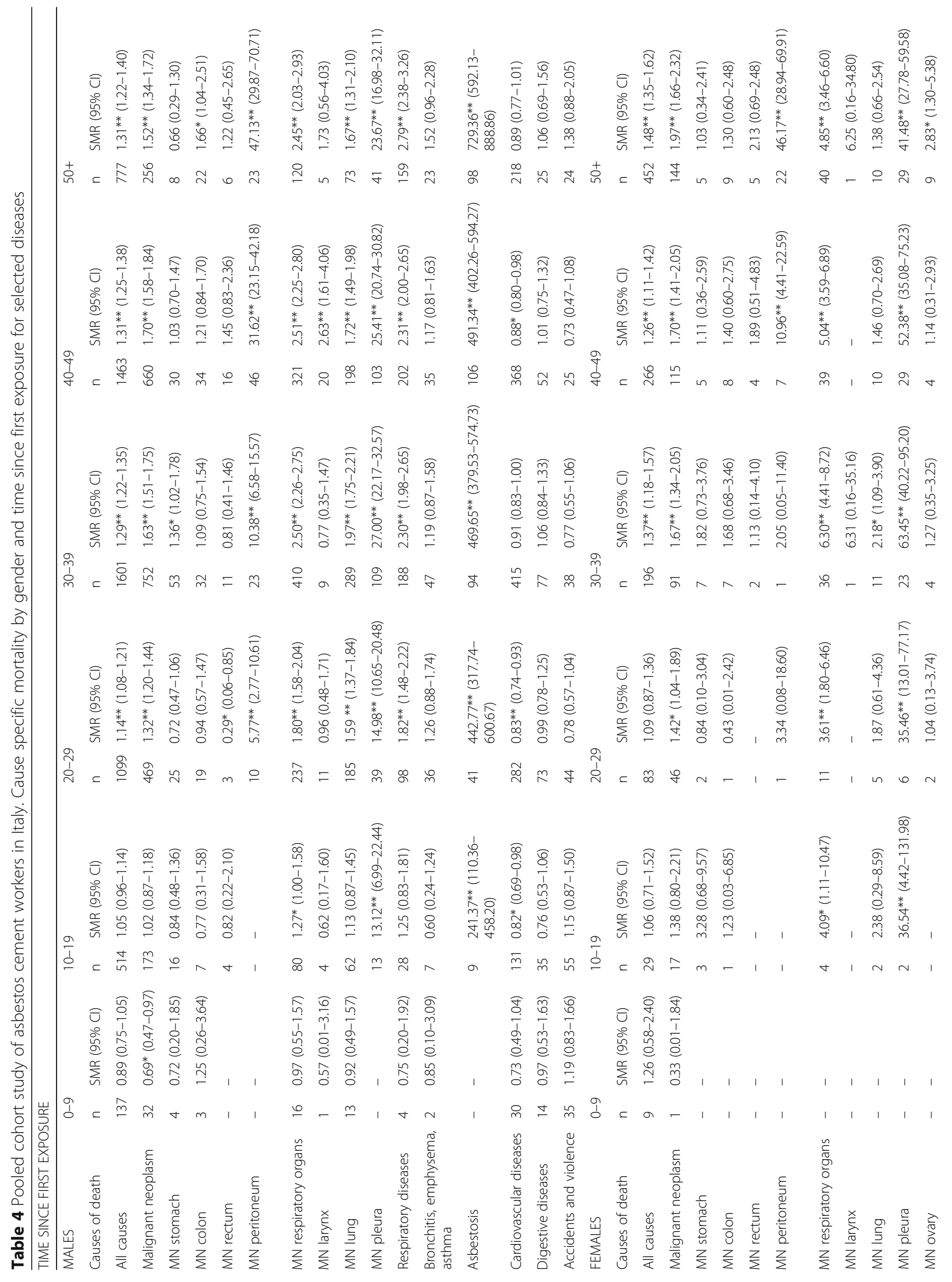




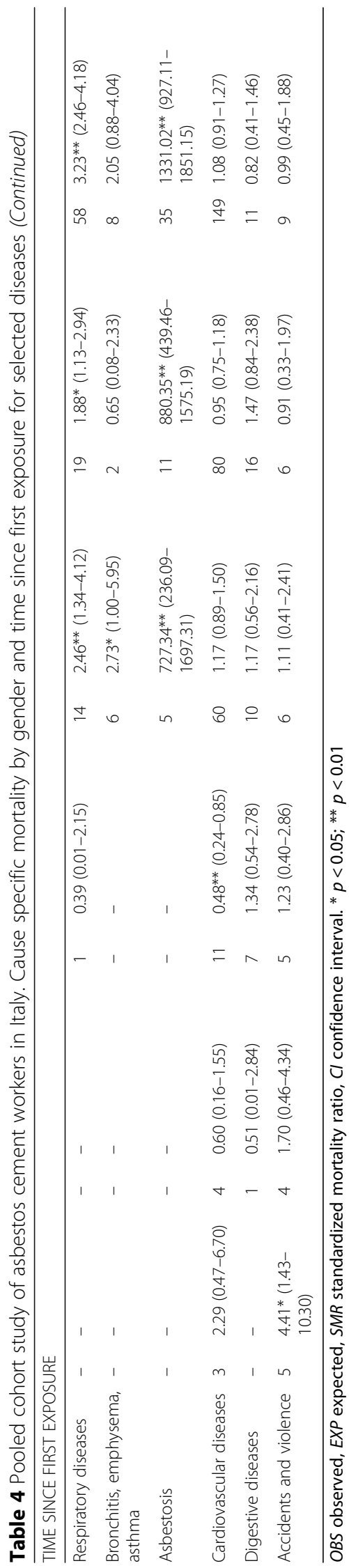


Table 5 Pooled cohort study of asbestos cement workers in Italy. Poisson regression analyses of mortality by gender and cumulative exposure for selected diseases

\begin{tabular}{|c|c|c|c|c|c|}
\hline & & & RR & $95 \% \mathrm{Cl}$ & $\begin{array}{l}\text { Other terms } \\
\text { in the model }\end{array}$ \\
\hline \multicolumn{6}{|l|}{ Pleural MN } \\
\hline \multirow[t]{7}{*}{ Men } & Cum.exposure & I tertile & 1 & & $\begin{array}{l}\text { age and } \\
\text { period }\end{array}$ \\
\hline & & II tertile & 2.41 & $1.61-3.61$ & \\
\hline & & III tertile & 4.88 & $3.18-7.48$ & \\
\hline & TSFE & $0-19$ years & 1 & & \\
\hline & & $20-29$ years & 2.08 & $1.08-4.01$ & \\
\hline & & 30-39 years & 4.40 & $2.26-8.54$ & \\
\hline & & $40-49$ years & 4.48 & $2.13-9.42$ & \\
\hline \multirow[t]{8}{*}{ Women } & Cum.exposure & I tertile & 1 & & $\begin{array}{l}\text { age and } \\
\text { period }\end{array}$ \\
\hline & & II tertile & 1.33 & $0.57-3.05$ & \\
\hline & & III tertile & 4.35 & $1.92-9.84$ & \\
\hline & TSFE & $0-19$ years & 1 & & \\
\hline & & $20-29$ years & 1.79 & $.35-9.10$ & \\
\hline & & 30-39 years & 4.59 & $0.99-21.36$ & \\
\hline & & $40-49$ years & 4.80 & $0.96-24.06$ & \\
\hline & & $50+$ years & 4.59 & $0.82-25.73$ & \\
\hline \multicolumn{6}{|c|}{ Peritoneal MN } \\
\hline \multirow[t]{7}{*}{ Men } & Cum.exposure & I tertile & 1 & & period \\
\hline & & II tertile & 5.58 & $1.66-18.80$ & \\
\hline & & III tertile & 16.62 & $5.01-55.10$ & \\
\hline & TSFE & $0-29$ years & 1 & & \\
\hline & & $30-39$ years & 4.14 & $1.86-9.19$ & \\
\hline & & $40-49$ years & 11.21 & $4.88-25.76$ & \\
\hline & & $50+$ years & 14.45 & $5.67-36.86$ & \\
\hline \multirow[t]{7}{*}{ Women } & Cum.exposure & I tertile & 1 & & period \\
\hline & & II tertile & 0.52 & $0.09-3.17$ & \\
\hline & & III tertile & 4.25 & $0.94-19.28$ & \\
\hline & TSFE & $0-29$ years & 1 & & \\
\hline & & $30-39$ years & 1.45 & $0.09-23.99$ & \\
\hline & & $40-49$ years & 10.35 & $1.15-93.36$ & \\
\hline & & $50+$ years & 37.25 & $4.13-336.26$ & \\
\hline \multicolumn{6}{|l|}{ Lung MN } \\
\hline \multirow[t]{8}{*}{ Men } & Cum.exposure & I tertile & 1 & & $\begin{array}{l}\text { age and } \\
\text { period }\end{array}$ \\
\hline & & II tertile & 1.15 & $0.92-1.43$ & \\
\hline & & III tertile & 1.82 & $1.45-2.29$ & \\
\hline & TSFE & $0-19$ years & 1 & & \\
\hline & & 20-29 years & 1.74 & $1.31-2.32$ & \\
\hline & & $30-39$ years & 2.22 & $1.63-3.01$ & \\
\hline & & $40-49$ years & 1.76 & $1.23-2.52$ & \\
\hline & & $50+$ years & 1.34 & $0.87-2.07$ & \\
\hline
\end{tabular}


Table 5 Pooled cohort study of asbestos cement workers in Italy. Poisson regression analyses of mortality by gender and cumulative exposure for selected diseases (Continued)

\begin{tabular}{ccccc}
\hline & & RR & $95 \% \mathrm{Cl}$ & $\begin{array}{l}\text { Other terms } \\
\text { in the model }\end{array}$ \\
\hline Women & Cum.exposure & I tertile & 1 & $1.12-12.61$ \\
& II tertile & 3.75 & age \\
& III tertile & 2.25 & $0.63-8.07$ \\
\hline
\end{tabular}

Cumulative exposure expressed as Fibre-type-weighted-CEI (Index of cumulative exposure adjusted for the type of asbestos used), see text for details

Italy [4]. At our knowledge, this is the largest study in the world on asbestos cement workers. Other specific features of this study include a very long follow-up, more than 40 years, and a significant number of women, providing a substantial contribution to gender-specific analyses.

The follow-up results are satisfactory, with only 1.3\% of subjects with unknown status (lost or emigrated). Causes of death are known for over 95\% of decedents in both sexes. SMR analyses are based on regional mortality rates, in order to increase the comparability between cohorts and reference rates. The decision to restrict the analyses to 1970 onwards depended on the availability of reference mortality rates [37] and not on the quality of cohort data, which is overall high. For consistency of the design and analyses, we decided to apply the restriction also to the internal analyses with Poisson regression, even if it was not strictly necessary.

Asbestos exposure could not be assessed on an individual basis, because of the lack of individual data on jobs and work activities for members of almost all cohorts. Therefore, we based our exposure assessment on the average index (AEI) representing the plant and period workforce average exposure, obtained from the estimation of exposure for workers with direct and indirect asbestos exposure. We calculated the individual cumulative exposure index (CEI) of cohort members by applying the AEI specific for plant and period to their duration and timing of employment. To take into account differences in the use of amphibole and chrysotile asbestos by plant and period, indices were weighted for the proportion of the different fibre types and their estimated carcinogenic potency factor for pleural MM [41]. More recent estimates of fibre type potency were used in sensitivity analyses [42], although the data base used for that review was criticized for incompleteness [43], and no relevant difference was observed.

The study was based on mortality data, as cancer registries in Italy do not cover the population and period of interest for the study. There was no specific code for $\mathrm{MM}$ of peritoneum and pleura in the 8th and 9th ICD, and ICD $10^{\text {th }}$ is in use from 2003 in Italy. The use of mortality data could have caused a misclassification of MM with other cancers, in particular metastasis or lung cancer, in both directions. Therefore, literature evidence was searched to evaluate this possible bias. The sensitivity of death certificates for the identification of MM was explored in a meta-analysis by Kopylev et al. [47], who observed an underestimation of MM incidence from mortality data. This observation was supported by other studies not included in that revision: $74,5 \%$ of pleural MM cases could be identified from mortality records in Italy [48] and $87 \%$ in Southern England [49]. Similar results were observed by Conti et al., who compared mortality and incidence for peritoneal MM in Italy [50]. Some studies in our cohort [12, 14, 16] had performed a record linkage with the Italian Mesothelioma Registry data: results were satisfactory and showed that SMRs did not over-estimate SIRs of MM.

Mortality for "All causes" and "All MN" showed in both sexes a statistically significant increase, in general and in stratified analyses, in particular according to cumulative exposure and TSFE. The pattern was observed also for the workers who started employment in the more recent periods. This overall result, which is not affected by questions regarding classification of causes of deaths, shows macroscopically the consequences of the exposure in the asbestos-cement production industries. In total, the cohorts in study showed an excess of 1255.6 deaths, corresponding to a $19 \%$ increase of overall mortality. This large excess should be evaluated also with consideration of the evidence of a relevant HWE, as shown by the low mortality for cardiovascular and neurological diseases and by the low mortality observed in the first ten years of TSFE.

A statistically significant increase in mortality was observed in both sexes for pleural, peritoneal, and lung $\mathrm{MN}$, consistent with the recent IARC evaluation [1]: overall the number of deaths were 394, 133 and 858, and the corresponding attributable proportions [51] for these conditions were respectively 96,93 and 40\%, similar for men and women. The point estimate of SMRs in women are higher than in men for peritoneal and pleural MN. These results do not reflect a higher risk or an increased sensitivity to asbestos, but rather denote the lower female reference mortality rates in general population [37].

Analyses by cumulative exposure showed a statistically significant trend for pleural and peritoneal MN and for lung cancer, providing additional support to the evidence of dose response relation for MM [52] and for lung 


\section{a Pleural MN}

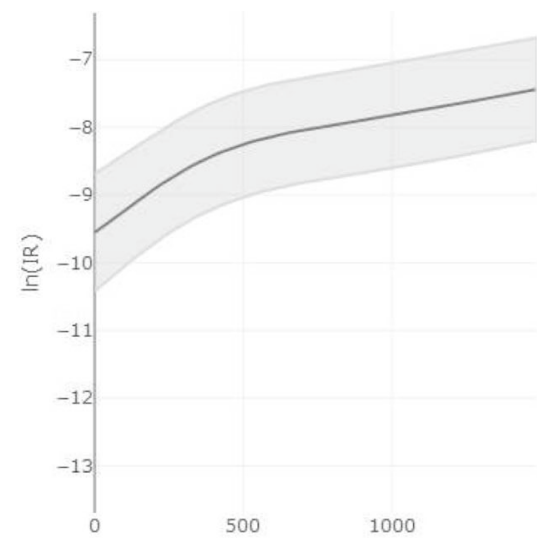

fibre - type - CAEI

b

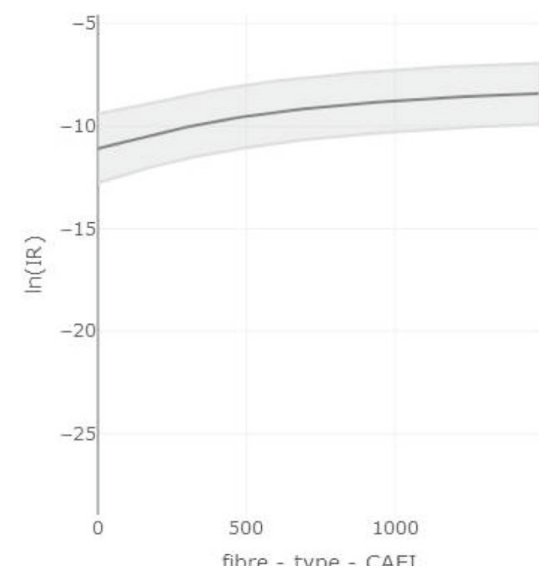

fibre - type - CAEI

C

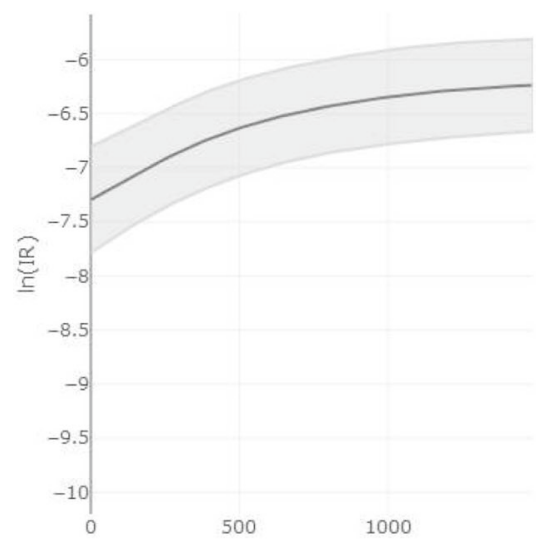

fibre - type - CAEI
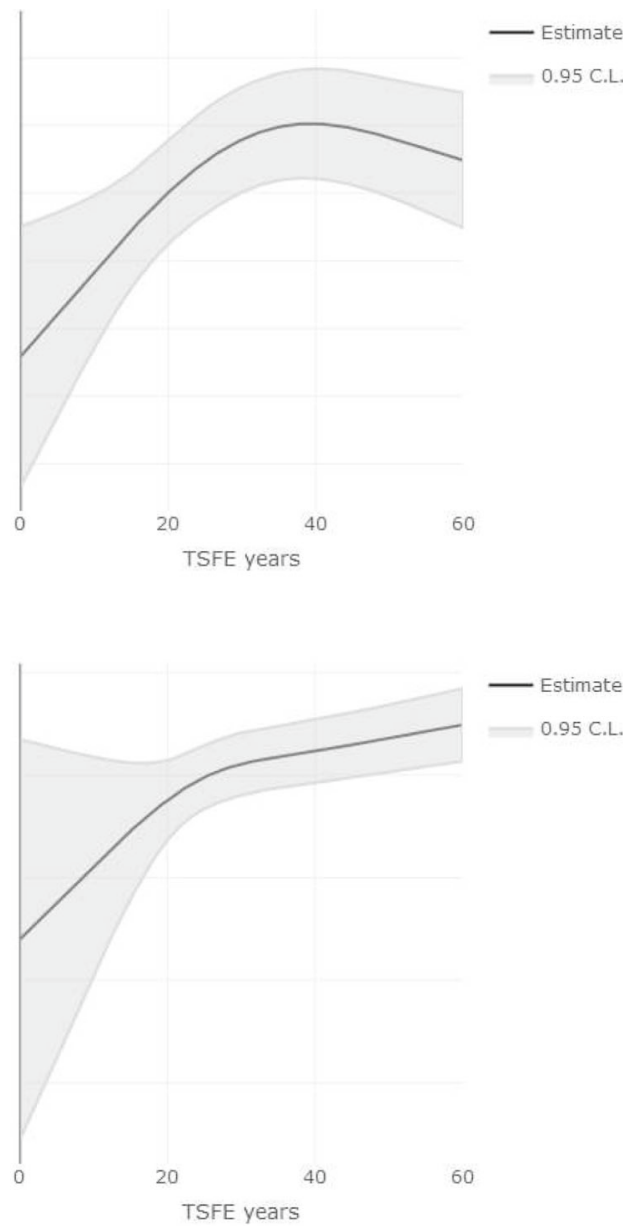

TSFE years

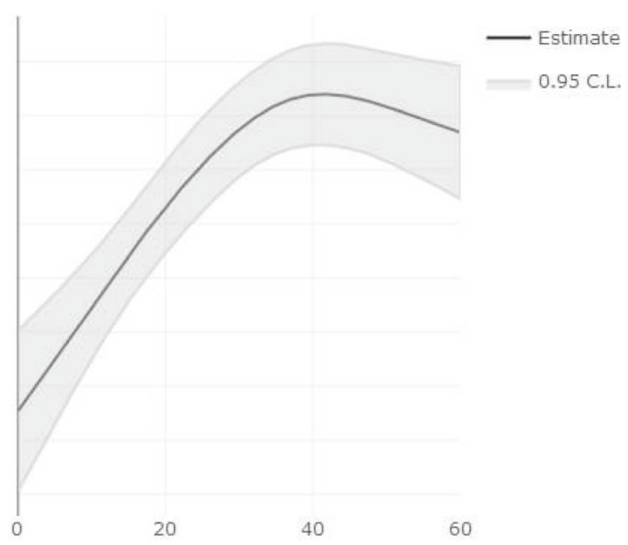

TSFE years

Fig. 2 Pooled cohort study of asbestos cement workers in Italy. Restricted cubic spline (4 degrees) for pleural (a), peritoneal (b), and lung (c) MN mortality on Fibre-type-Cumulative Exposure Index (fibre-type-weighted CEI) and Time Since First Exposure (TSFE). The analyses were adjusted for fibre-type-weighted-CEI, TSFE and period. The plots are trimmed at the $90^{\circ}$ percentile of the cumulative distribution of the fibre-type-weighted-CEI 
cancer $[53,54]$. Poisson regression analyses showed similar RRs in men and women for pleural MN. For peritoneal MN, men had higher RRs than women at the same levels of cumulative exposure, however the number of female cases was limited and confidence intervals were wide and overlapping between the two group.

In our study, SMRs for both pleural and lung MN increased up to 30-39 years of TSFE and showed a plateau thereafter, with some fluctuations in women. On the contrary, the SMR for peritoneal MN increased monotonically in both genders. The same trends were observed also in the Poisson regression analyses using splines. As regards $\mathrm{MM}$, our results contradict the traditional models of asbestos carcinogenesis, that predicted an unlimited increase of $\mathrm{MM}$ rates over time from the beginning of asbestos exposure, according to a power function of TSFE $[55,56]$ and did not differentiate between the anatomical location of MM $[55,56]$. On the contrary, our results supported the evidence of a flattening in the trend of MM rates with TSFE and showed a difference between pleural and peritoneal $\mathrm{MN}$, in agreement with the more recent evidence showing a reduction of the increasing incidence trend after long latency for pleural but not for peritoneal MM $[14,29-31,57,58]$. The only exception in the recent literature was a follow-up study of former Polish asbestos workers participating in a health surveillance program, among whom a continued increase in the risk of pleural MM by TSFE was reported [59]. The interpretation of such study is difficult as results may have been biased by the different participation of subjects with symptoms or otherwise interested in health assessment. A biological interpretation of the evidence is that asbestos fibres are slowly cleared from the lungs. For amphibole asbestos, a constant annual elimination rate in the order of up to $10 \%$ was estimated in different studies [60-66]. Toxicological [67] and histological studies [66] showed a different clearance of the fibres, especially in subjects with chrysotile only exposure. The same explanation holds also for lung cancer, showing results consistent with the reduction of risk following a reduction of lung burden. The difference between pleura and peritoneum is also consistent with reports from other studies [14, 29, 30, 68], and can be explained by the different distribution of asbestos fibers in the body, that interest the pleura more directly and the peritoneum only after internal transportation [69].

Ovarian cancer overall showed a modest increase in mortality, with SMR similar to the RR measured in meta-analyses [70, 71] and in a preliminary analysis of the present cohorts, including other industrial sectors as well as the asbestos cement [36]. However, we observed a significant increase in women in the III tertile of cumulative exposure, in those who started employment before 1950, after more than 30 years of employment, or TSFE longer than 50 years.
We observed only a slight increase of laryngeal cancer mortality in both sexes. In men, the SMRs were higher in the higher classes of TSFE (40-49 and 50+ years) but we did not see a relation with cumulative exposure. In women, the two observed cases were in the mid and upper tertile of cumulative exposure and in the upper categories of TSFE. In summary, our cohort results provide little support to the association with laryngeal cancer, contrary to the two recent reviews by the Institute of Medicine [72] and by Peng et al. [73]. Our study was limited by the use of mortality data and the absence of information on smoking and drinking. Mortality analyses are not very sensitive for diseases with long survival, such as laryngeal cancer in recent periods [74]. A possible (negative) confounding by smoking and drinking habits cannot be ruled out: the mortality analyses showed a reduced mortality for cardiovascular deaths, suggesting that smoking habits were not worse than in the general population, although the evidence in this respect is limited.

Overall this large cohort did not show an excess of $\mathrm{MN}$ of digestive organs other than the peritoneal $\mathrm{MN}$ and provide little support to the causality of asbestos exposure for these neoplasms, contrary to recent results from meta-analyses or other cohorts [72, 75]. However, it should be noticed that for colon and rectum $\mathrm{MN}$ an excess was shown after TSFE longer than 50 years. As discussed for larynx cancer, these tumours have long survival and mortality could not be a sensitive indicator of risk.

For asbestosis, we observed in both sexes a clear association with cumulative exposure, a result that corroborates on the quality of our exposure assessment. A specific work on asbestosis in this cohort study is in progress, however present analyses already provide some relevant results. The increase in mortality from asbestosis was large, in particular among women. We believe that these data do not express a real gender difference but reflect the very low female reference mortality rates from these diseases in Italy [37]. Five cases of death attributed to asbestosis were observed in men in the lowest tertile of cumulative exposure, corresponding to the cumulative exposure 'up to 54.0' $\mathrm{f} / \mathrm{ml}^{*}$ years for fibretype-weighted-CEI. Mortality from asbestosis by period of first employment declined but remained higher than expected until the most recent periods, with one case observed among workers who started activity after 1980, possibly suggesting high exposures also in the last periods of industrial use of asbestos in Italy. Mortality from asbestosis was assessed on the basis of the underlying cause of death and no best-evidence assignment of the cause of death has been attempted. Previous reports from some of the cohorts included in the present study $[14,16]$, showed that additional cases had been reported when concomitant causes of death were considered, 
therefore an underestimation of SMRs is possible in this study. With consideration to the possible misclassification of outcome, we underline that 32 deaths in men and 1 in women had been recorded as "other pneumoconiosis" in the death certificate, possibly attributable to incorrect reporting of asbestosis, as SMRs increased with increasing cumulative exposure.

The possible occurrence of HWE was analysed with consideration of total mortality and of the causes of death reported in the literature as most often associated with it [38], namely cardiovascular, respiratory, neurological, psychiatric, digestive and genitourinary diseases. Overall mortality was higher than expected, because of the large increase of ARD mortality. The pattern of specific causes of death showed a marked HWE effect; in particular results for cardiovascular diseases mortality were corresponding to a HWE from selection at hire and possibly an additionally healthy worker survivor effect [38]: cardiovascular disease mortality was not associated with cumulative exposure and remained lower than expected in the analyses by TSFE.

We do not have any individual information on smoking habits for the study, as often happens in occupational cohort investigations. However, the risk for cardiovascular diseases, strongly associated to smoking, is decreased in the cohort even after long TSFE, suggesting that the proportion of smokers was at least not larger than in the general population. Our findings on lung cancer are, therefore, unlikely due to uncontrolled confounding from smoking. We were, however, unable to assess the combined effect of tobacco smoking and asbestos $[54,76]$.

\section{Conclusions}

Our study contributes to the evidence of increased mortality risk due to asbestos exposure for MN of pleura, peritoneum, lung and ovary, as well as for asbestosis, all increasing with cumulative exposure. We have not detected an excess risk of larynx, pharynx, and stomach $\mathrm{MN}$, except for larynx cancer after very long latencies. In summary, ARD mortality was higher than expected in both genders. Mortality from cardiovascular diseases was significantly lower than expected in men, suggesting an HWE but also that the prevalence of smokers among asbestos-cement workers was not larger than in the general population. Mortality for smoking-related neoplasms different from lung and larynx cancer was not increased.

Pleural and peritoneal MN showed a clear exposureresponse relation and had different trends with TSFE. The TSFE analysis showed a monotonic increase of mortality in relation to TSFE for peritoneal $\mathrm{MN}$, while pleura and lung MN mortality reached a plateau about 40 years after first exposure. The increase of MM rates by TSFE predicted by traditional models might be attenuated, due to the effect of the clearance of fibres.

These results underline the increased risk of ARDs in the asbestos cement production and are therefore of special relevance also for the countries that have not banned the use of asbestos.

\section{Additional file}

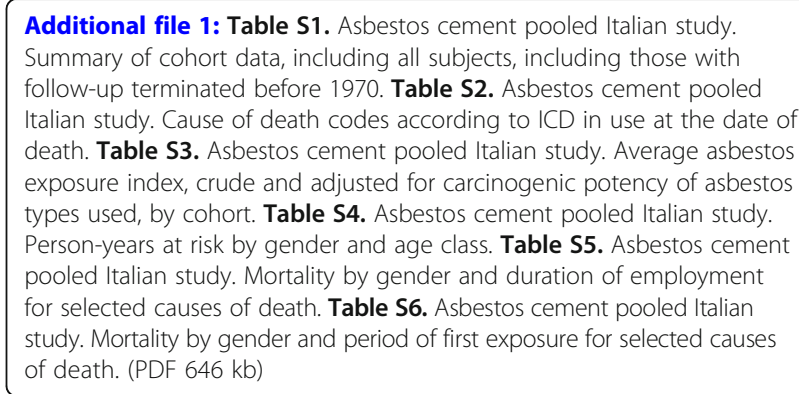

\section{Abbreviations}

AEl: Average Exposure Index; ARD: Asbestos Related Disease; CEl: Cumulative Average Exposure Index; Cl: Confidence Interval; FU: Follow-up; HWE: Healthy Worker Effect; IARC: International Agency for Research on Cancer;

ICD: International Classification of Diseases; LHA: Local Health Authority; MM: Malignant mesothelioma; MN: Malignant neoplasm; SMR: Standardized Mortality Rate; TSFE: Time Since First Exposure

\section{Acknowledgements}

The authors wish to thank Prof. Loredana Musmeci from ISS for their contribution to the research.

The working group includes: Lisa Bauleo ${ }^{18}$, Antonio Baldassarre ${ }^{19}$, Carol Brentisci ${ }^{7}$, Barbara Cortini ${ }^{11}$, Stefania Curti ${ }^{20}$, Manuela Gangemi ${ }^{7}$, Giuseppe Gorini $^{11}$, Patrizia Legittimo ${ }^{20}$, Francesco Marinelli ${ }^{20}$, Pasqualina Marinilli ${ }^{21}$, Stefano Mattioli ${ }^{20}$, Marina Musti ${ }^{22}$, Chiara Panato ${ }^{14}$, Venere Leda Mara Pavone $^{21}$, Alessandra Ranucci ${ }^{2,3}$, Elisa Romeo ${ }^{18}$, Corrado Scarnato ${ }^{21}$, Cinzia Storchi ${ }^{1}$, Antonella Stura ${ }^{7}$, Simona Verdi ${ }^{11}$

${ }^{1}$ Epidemiology Unit, Azienda Unità Sanitaria Locale - IRCCS di Reggio Emilia, Reggio Emilia, Italy

${ }^{2}$ Unit of Medical Statistics and Cancer Epidemiology, Department of Translational Medicine, University of Eastern Piedmont, Novara, Italy ${ }^{3} \mathrm{CPO}$-Piedmont, Novara, Italy

${ }^{7}$ Unit of Cancer Epidemiology, CPO Piedmont and University of Turin, Turin, Italy

${ }^{9}$ National Cancer Institute IRCCS Fondazione Pascale, Naples, Italy

${ }^{11}$ Occupational \& Environmental Epidemiology Unit - Institute for Cancer

Research, Prevention and Clinical Network (ISPRO), Florence, Italy

${ }^{14}$ Mesothelioma Register of the Veneto Region, Regional Epidemiologic

System, Local Health Unit 6, Padua, Italy

${ }^{18}$ Department of Epidemiology, Lazio Regional Health Service, Rome, Italy

${ }^{19}$ Occupational Medicine Unit, Careggi University Hospital, Florence, Italy

${ }^{20}$ Department of Medical and Surgical Sciences, University of Bologna,

Bologna, Italy

${ }^{21}$ Department of Public Health, Prevention and Security Area Work

Environments, Local Health Authority, Bologna, Italy

${ }^{22}$ Interdisciplinary Department of Medicine, Occupational Medicine "B.

Ramazzini", University of Bari, Bari, Italy

\section{Authors' contributions}

FL Design of the analysis project for this article, conduct of the study, drafting and and critical revision of the article. DF Design of the study, design and conduct of data analysis and drafting of the article. SS Estimation of exposure, drafting and critical revision of the article. AA Estimation of exposure, drafting and critical revision of the article. FC Design of the study, conduct of the study and critical revision of the article. AMN Design of the study, conduct of the study and critical revision of the article. EO Design of 
the study, conduct of the study and critical revision of the article. MV Design of the study, conduct of the study and critical revision of the article. FBA Planning and overview of data analysis and critical revision of the article. TC Data management, data analysis and critical revision of the article. DM Design of the study, evaluation of exposure information and critical revision of the article. LM Design of the study, conduct of the study and critical revision of the article. FR Conduct of the study and critical revision of the article. OS Design of the study, estimation of exposure and critical revision of the article. SM Design of the study, conduct of the study and critical revision of the article. RP Design of the study, overview of mortality data analyses and critical revision of the article. DA Data analyses, writing and critical revision of the article. ST Data analysis and critical revision of the article. EC Design of the study, conduct of the study and critical revision of the article. LM Design of the study, conduct of the study and critical revision of the article. PP Design of the study, conduct of the study and critical revision of the article. AP Design of the study, conduct of the study and critical revision of the article. VB Design of the study, conduct of the study and critical revision of the article. EM Design of the study, conduct of the study and critical revision of the article. PG Design of the study and of data analysis and critical revision of the article. LB Design of the study, conduct of the study and critical revision of the article. AM Design of the study, incidence data collection coordination, and critical revision of the article. SM Design of the study, INAIL data collection coordination, and critical revision of the article. CM PI the study, overview of the study and critical revision of the article. All authors read and approved the final manuscript.

\section{Authors' information}

Corrado Magnani is the Study Coordinator.

\section{Funding}

The cohort study was conducted thanks to grants from the 'Asbestos Project' of the Italian National Institute of Health (ISS), [Current research 2012: asbestos project. Operative Unit 2 "Amedeo Avogadro" University of Eastern Piedmont, Novara, Research Line 1,2.] and from the INAIL [Piano Ricerca 2016-2018, "Programma Speciale Amianto", Ricerca BRIC id 55 and Ricerca BRIC id 59].

\section{Availability of data and materials}

The datasets used and analysed during the current study are available from the corresponding author on reasonable request.

\section{Ethics approval and consent to participate}

The main study was approved by the University of Eastern Piedmont's Ethical Review Board (authorization CE 112/13, July 12th, 2013), while the principal investigators (PI) of each cohort submitted the individual studies to the corresponding local boards.

\section{Competing interests}

The authors declare that they have no competing interests.

The following authors reported that they served as expert witness in court trials on asbestos related diseases: AA, AB, FB-A, LB, CM, LM, SM, EM, DM, $M M, E O, V P, S S$.

\section{Author details}

'Epidemiology Unit, Azienda Unità Sanitaria Locale - IRCCS di Reggio Emilia, Reggio Emilia, Italy. ${ }^{2}$ Unit of Medical Statistics and Cancer Epidemiology, Department of Translational Medicine, University of Eastern Piedmont, via Solaroli 17, 28100 Novara, Italy. ${ }^{3}$ CPO-Piedmont, Novara, Italy. ${ }^{4}$ Unit of Epidemiology and Statistics, Local Health Unit of Barletta-Andria-Trani, Barletta, Italy. ${ }^{5}$ Department of Public Health, Experimental and Forensic Medicine, University of Pavia, and ICS Maugeri IRCCS, Pavia, Italy. ${ }^{6}$ Department of Pharmaceutical Sciences, University of Eastern Piedmont, and CPO Piedmont, Novara, Italy. ${ }^{7}$ Unit of Cancer Epidemiology, CPO Piedmont and University of Turin, Turin, Italy. ${ }^{8}$ Regional Agency for Prevention, Environment and Energy Emilia-Romagna, Provincial Office of Reggio Emilia, Reggio Emilia, Italy. ${ }^{9}$ National Cancer Institute IRCCS Fondazione Pascale, Naples, Italy. ${ }^{10}$ Department of Biology and Biotechnologies "Charles Darwin", Sapienza University, Rome, Italy. ${ }^{11}$ Occupational \& Environmental Epidemiology Unit - Institute for Cancer Research, Prevention and Clinical Network (ISPRO), Florence, Italy.

${ }^{12}$ Prevention Department, ASUR Marche, Senigallia, Italy. ${ }^{13}$ UOSD Servizio di
Epidemiologia AULSS6 EUGANEA, Padua, Italy. ${ }^{14}$ Mesothelioma Register of the Veneto Region, Regional Epidemiologic System, Local Health Unit 6 , Padua, Italy. ${ }^{15}$ Apulia Regional Agency for Health and Social Policies - ARESS Puglia, Bari, Italy. ${ }^{16}$ Italian Workers' Compensation Authority (INAIL),

Department of Occupational and Environmental Medicine, Epidemiology and Hygiene, Unit of Occupational and Environmental Epidemiology, Italian Mesothelioma Register, Rome, Italy. ${ }^{17}$ Interdepartmental Centre G. Scansetti for Studies on Asbestos and other Toxic Particulates, University of Turin, Turin, Italy.

Received: 22 May 2019 Accepted: 30 July 2019

Published online: 07 August 2019

\section{References}

1. IARC International Agency for Research on Cancer. Arsenic, metals, fibres, and dusts. IARC Working Group on the Evaluation of Carcinogenic Risks to Humans. IARC Monogr Eval Carcinog Risks Hum. 2012;100(Pt C):11-465.

2. Health Effects Institute. Asbestos in public and commercial buildings: a literature review and synthesis of current knowledge. Cambridge: Health Effects Institute-Asbestos Research; 1991.

3. Albin M, Magnani C, Krstev S, et al. Asbestos and cancer: an overview of current trends in Europe. Environ Health Perspect. 1999;107(Suppl 2):289-98.

4. Mirabelli D, Kauppinen T. Occupational exposure to carcinogens in Italy: an update of CAREX database. Int J Occup Environ Health. 2005;11:53-63.

5. Mirabelli D, Cavone D, Luberto F, et al. II comparto della produzione di Cemento Amianto. In: Marinaccio A, Binazzi A, Di Marzio D, et al., editors. Registro Nazionale dei Mesoteliomi Terzo Rapporto. Roma: Istituto Superiore per la Prevenzione e la Sicurezza sul Lavoro; 2010. p. 105-23.

6. Finkelstein MM. Absence of radiographic asbestosis and the risk of lung cancer among asbestos-cement workers: extended follow-up of a cohort. Am J Ind Med. 2010;53:1065-9.

7. Hughes JM, Weill H, Hammad YY. Mortality of workers employees in two asbestos cement manufacturing plant. Brit J Ind Med. 1987;44:161-74.

8. Tulchinsky TH, Ginsberg GM, Iscovich J, et al. Cancer in ex-asbestos cement workers in Israel, 1953-1992. Am J Ind Med. 1999;35:1-8.

9. Sarto F, Zambon P, Mastrangelo G, et al. Studio epidemiologico prospettico storico sulla mortalità per tumori di una coorte di soggetti esposti a cemento-asbesto. Epidemiol Prev. 1982;17-18:58-9.

10. Pettinari A, Mengucci R, Belli S, Comba P. Mortality of workers employed at an asbestos cement manufacturing plant in Senigallia. Med Lav. 1994;85: 223-30.

11. Coviello V, Carbonara M, Bisceglia $L$, et al. Mortality in a cohort of asbestos cement workers in Bari. Epidemiol Prev. 2002;26:65-70.

12. Luberto F, Amendola P, Belli S, et al. Mortality study of asbestos cement workers in Emilia-Romagna. Epidemiol Prev. 2004;28:239-46.

13. Raffaelli I, Festa G, Costantini AS, Leva G, Gorini G. Mortality in a cohort of asbestos cement workers in Carrara, Italy. Med Lav. 2007;98:156-63.

14. Magnani C, Ferrante D, Barone-Adesi F, et al. Cancer risk after cessation of asbestos exposure. A cohort study of Italian asbestos cement workers. Occup Environ Med. 2008;65:164-70.

15. Ferrante $D$, Bertolotti $M$, Todesco $A$, et al. Mortality among asbestos cement workers: the cohort of the S.a.C.a. plant in Cavagnolo (Italy). Biomed Stat Clin Epidemiol. 2008;2:171-7.

16. Menegozzo S, Comba P, Ferrante D, et al. Mortality study in an asbestos cement factory in Naples, Italy. Ann Ist Super Sanita. 2011;47:296-304.

17. Fazzo L, Nicita C, Cernigliaro A, et al. Mortalità per cause asbesto-correlate e incidenza del mesotelioma fra i lavoratori del cemento-amianto di San Filippo del Mela (Messina). Epidemiol Prev. 2010;34:87-92.

18. Oddone E, Ferrante D, Tunesi S, Magnani C. Mortality in asbestos cement workers in Pavia, Italy: a cohort study. Am J Ind Med. 2017;60:852-66.

19. Thomas HF, Benjamin IT, Elwood PC, Sweetnam PM. Further follow-up study of workers from an asbestos cement factory. Brit J Ind Med. 1982;39:273-6.

20. Alies-Patin AM, Valleron AJ. Mortality of workers in a French asbestos cement factory, 1940-82. Brit J Ind Med. 1985;42:219-25.

21. Ohlson C-G, Hogstedt C. Lung cancer among asbestos cement workers. A Swedish cohort study and a review. Brit J Ind Med. 1985;42:397-402.

22. Gardner MJ, Winter PD, Pannett B, Powell CA. Follow up study of workers manufacturing chrysotile asbestos cement products. Brit J Ind Med. 1986;43:726-32. 
23. Raffn E, Lynge $E$, Juel K, Korsgaard B. Incidence of cancer and mortality among employees in the asbestos cement industry in Denmark. Brit J Ind Med. 1989:46:90-6.

24. Albin M, Jakobsson K, Attewell R, Johansson L, Welinder $H$. Mortality and cancer morbidity in cohorts of asbestos cement workers and referents. Brit J Ind Med. 1990:47:602-10.

25. Szeszenia Dabrowska N, Wilczynska U, Szymczak W. Mortality of workers in two asbestos-cement plants in Poland. Int J Occup Med Environ Health. 2000;13:121-30.

26. Neuberger M, Vutuc C. Three decades of pleural cancer and mesothelioma registration in Austria where asbestos cement was invented. Int Arch Occup Environ Health. 2003;76:161-6.

27. Smailyte G, Kurtinaitis J, Andersen A. Cancer mortality and morbidity among Lithuanian asbestos-cement producing workers. Scand J Work Environ Health. 2004;30:64-70.

28. Sichletidis L, Chloros D, Spyratos D, et al. Mortality from occupational exposure to relatively pure chrysotile: a 39-years study. Respiration. 2009;78:63-8

29. Barone-Adesi F, Ferrante D, Bertolotti $M$, et al. Long-term mortality from pleural and peritoneal cancer after exposure to asbestos: possible role of asbestos clearance. Int J Cancer. 2008;123:912-6.

30. Reid A, de Klerk NH, Magnani C, et al. Mesothelioma risk after 40 years since first exposure to asbestos: a pooled analysis. Thorax. 2014;69:843-50.

31. Pira E, Romano C, Violante FS, et al. Updated mortality study of a cohort of asbestos textile workers. Cancer Med. 2016;5:2623-8.

32. Berman DM. Asbestos and health in the third world: the case of Brazil. Int J Health Serv. 1986;16:253-63.

33. Giannasi F, Thébaud-Mony A. Occupational Exposures to Asbestos in Brazil. Int J Occup Environ Health. 1997;3:150-7.

34. Ansari FA, Bihari V, Rastogi SK, et al. Environmental health survey in asbestos cement sheets manufacturing industry. Indian J Occup Environ Med. 2007; 11:15-20.

35. Burki T. Health experts concerned over India's asbestos industry. Lancet. 2010;375:626-7.

36. Ferrante D, Chellini E, Merler E, et al. Italian pool of asbestos workers cohorts: mortality trends of asbestos related neoplasms after long latency. Occup Environ Med. 2017;74:897-8.

37. Pirastu R, Ranucci A, Consonni D, et al. Reference rates for cohort studies in Italy: an essential tool in occupational and residential cohort studies. Med Lav. 2016;107:473-7.

38. Checkoway H, Pearce NE, Crawford-Brown DJ. Research methods in occupational epidemiology. New York: Oxford University Press; 1989. p. 78-9. and 86-91

39. Patroni M, Trimarchi R, Andreoletti F, Foà V, Chiappino G. Occupational risk in asbestos cement industry. Med Lav. 1987:78:351-9.

40. Stewart PA, Stewart WF. Occupational case-control studies: II. Recommendations for exposure assessment. Am J Ind Med. 1994:26: 313-26.

41. Hodgson JT, Darnton A. Mesothelioma risk from chrysotile. Occup Environ Med. 2010;67:432.

42. Garabrant DH, Pastula ST. A comparison of asbestos fiber potency and elongate mineral particle (EMP) potency for mesothelioma in humans. Toxicol Appl Pharmacol. 2018:361:127-36.

43. Finkelstein MM. A comparison of asbestos fiber potency and elongate mineral particle (EMP) potency for mesothelioma in humans. Toxicol Appl Pharmacol. 2019;371:1-2

44. Breslow NE, Day NE. Statistical methods in cancer research. Volume II The design and analysis of cohort studies. Lyon: IARC Sci Publ 82; 1987. p. $1-406$

45. Harrell F. Regression modeling strategies: with applications to linear models, logistic and ordinal regression, and survival analysis. Berlin: Springer; 2015.

46. Team, R. C. R language definition. Vienna: R foundation for statistical computing; 2000.

47. Kopylev L, Sullivan PA, Vinikoor LC, Bateson TF. Monte Carlo analysis of impact of underascertainment of mesothelioma cases on underestimation of risk. Open Epidemiol J. 2011:4:45-53.

48. Bruno C, Comba P, Maiozzi P, et al. Accuracy of death certification of pleural mesothelioma in Italy. Eur J Epidemiol. 1996;12:421-3.

49. Okello C, Treasure T, Nicholson AG, Peto J, Møller H. Certified causes of death in patients with mesothelioma in south East England. BMC Cancer. 2009;9:28
50. Conti S, Minelli G, Ascoli V, et al. Peritoneal mesothelioma in Italy: trends and geography of mortality and incidence. Am J Ind Med. 2015;58:1050-8

51. Rothman K. Modern Epidemiology. 1st ed. Boston \& Toronto: Little, Brown and co.; 1989. p. 38-40.

52. Novello $S$, Pinto $C$, Torri $V$, et al. The third Italian consensus conference for malignant pleural mesothelioma: state of the art and recommendations. Crit Rev Oncol Hematol. 2016;104:9-20.

53. Clin B, Morlais F, Launoy G, et al. Cancer incidence within a cohort occupationally exposed to asbestos: a study of dose--response relationships. Occup Environ Med. 2011;68:832-6.

54. Olsson AC, Vermeulen R, Schüz J, et al. Exposure-response analyses of Asbestos and lung Cancer subtypes in a pooled analysis of case-control studies. Epidemiology. 2017;28:288-99.

55. Newhouse ML, Berry G. Predictions of mortality from mesothelial tumours in asbestos factory workers. Br J Ind Med. 1976;33:147-51.

56. Peto J, Seidman H, Selikoff IJ. Mesothelioma mortality in asbestos workers: implications for models of carcinogenesis and risk assessment. Brit J Cancer. 1982:45:124-35.

57. Berry G. Models for mesothelioma incidence following exposure to fibers in terms of timing and duration of exposure and the biopersistence of the fibers. Inhal Toxicol. 1999;11:111-30.

58. Berry G, Reid A, Aboagye-Sarfo P, et al. Malignant mesotheliomas in former miners and millers of crocidolite at Wittenoom (Western Australia) after more than 50 years follow-up. Br J Cancer. 2012;106: 1016-20

59. Świątkowska B, Szeszenia-Dąbrowska N. Mesothelioma continues to increase even 40 years after exposure - evidence from long-term epidemiological observation. Lung Cancer. 2017;108:121-5.

60. Du Toit RSJ. An estimate of the rate at which crocidolite asbestos fibres are cleared from the lung. Ann Occup Hyg. 1991;35:433-8.

61. Churg A, Wright JL. Persistence of natural mineral fibers in human lungs: an overview. Environ Health Perspect. 1994;102(suppl 5):229-33.

62. Tossavainen A, Karjalainen A, Karhunen PJ. Retention of asbestos fibers in the human body. Environ Health Perspect. 1994;102(suppl 5):253-5.

63. De Klerk NH, Musk AW, Williams V, et al. Comparison of measures of exposure to asbestos in former crocidolite workers from Wittenoom Gorge, W. Australia. Am J Ind Med. 1996:30:579-87.

64. Berry $\mathrm{G}$, de Klerk NH, Reid A, et al. Malignant pleural and peritoneal mesotheliomas in former miners and millers of crocidolite at Wittenoom, Western Australia. Occup Environ Med. 2004;61:e14.

65. Berry G, Pooley F, Gibbs A, Harris JM, McDonald JC. Lung fiber burden in the Nottingham gas mask cohort. Inhal Toxicol. 2009;21:168-72.

66. Merler E, Somigliana A, Girardi P, Barbieri PG. Residual fibre lung burden among patients with pleural mesothelioma who have been occupationally exposed to asbestos. Occup Environ Med. 2017;74:218-27.

67. Churg A, Wright JL. Fibre content of lung in amphibole- and chrysotileinduced mesothelioma: implications for environmental exposure. IARC Sci Publ. 1989:90:314-8.

68. Hodgson JT, Darnton A. The quantitative risks of mesothelioma and lung cancer in relation to asbestos exposure. Ann Occup Hyg. 2000; 44:565-601.

69. Miserocchi G, Sancini G, Mantegazza F, Chiappino G. Translocation pathways for inhaled asbestos fibers. Environ Health. 2008;7:4. https://doi.org/10.11 86/1476-069X-7-4.

70. Camargo MC, Stayner LT, Straif K, et al. Occupational exposure to asbestos and ovarian cancer: a meta-analysis. Environmen Health Perspect. 2011:119:1211-7.

71. Reid A, de Klerk N, Musk AW. Does exposure to asbestos cause ovarian cancer? A systematic literature review and meta-analysis. Cancer Epidemiol Biomark Prev. 2011;20:1287-95.

72. Institute of Medicine (US). Committee on Asbestos: selected Health Effects. Washington: National Academies Press (US); 2006. https://www.ncbi.nlm.nih. gov/books/NBK20326/

73. Peng WJ, Mi J, Jiang YH. Asbestos exposure and laryngeal cancer mortality. Laryngoscope. 2016;126:1169-74.

74. Gatta G, Botta L, Sánchez MJ, Anderson LA, Pierannunzio D, Licitra L, EUROCARE Working Group. Prognoses and improvement for head and neck cancers diagnosed in Europe in early 2000s: The EUROCARE-5 populationbased study. Eur J Cancer. 2015;51:2130-43. 
75. Boulanger M, Morlais F, Bouvier V, et al. Digestive cancers and occupational asbestos exposure: incidence study in a cohort of asbestos plant workers. Occup Environ Med. 2015;72:792-7.

76. Wraith D, Mengersen K. A Bayesian approach to assess interaction between known risk factors: the risk of lung cancer from exposure to asbestos and smoking. Stat Methods Med Res. 2008;17:171-89.

\section{Publisher's Note}

Springer Nature remains neutral with regard to jurisdictional claims in published maps and institutional affiliations.

Ready to submit your research? Choose BMC and benefit from:

- fast, convenient online submission

- thorough peer review by experienced researchers in your field

- rapid publication on acceptance

- support for research data, including large and complex data types

- gold Open Access which fosters wider collaboration and increased citations

- maximum visibility for your research: over $100 \mathrm{M}$ website views per year

At BMC, research is always in progress.

Learn more biomedcentral.com/submissions 